\title{
Stage-dependent expression of PI3K/Akt-pathway genes in neuroblastoma
}

\author{
SUSANNE FRANSSON $^{1}$, FRIDA ABEL $^{1}$, PER KOGNER $^{2}$, TOMMY MARTINSSON $^{1}$ and KATARINA EJESKÄR ${ }^{1,3}$ \\ ${ }^{1}$ Department of Medical and Clinical Genetics, Sahlgrenska Cancer Center, Gothenburg University, Gothenburg; \\ ${ }^{2}$ Childhood Cancer Research Unit, Department of Women's and Children's Health, Karolinska Institute, Stockholm; \\ ${ }^{3}$ School of Life Sciences, University of Skövde, Skövde, Sweden
}

Received August 24, 2012; Accepted October 5, 2012

DOI: $10.3892 /$ ijo.2012.1732

\begin{abstract}
The phosphoinositide-3 kinase (PI3K) pathway plays a critical role in cancer cell growth and survival and has also been implicated in the development of the childhood cancer neuroblastoma. In neuroblastoma high mRNA expression of the PI3K catalytic isoform PIK3CD is associated to favorable disease. Yet, activation of Akt is associated with poor prognosis. Since the contribution of the numerous members of this pathway to neuroblastoma pathogenesis is mainly unknown, genes of the PI3K/Akt pathway were analyzed at the mRNA level through microarrays and quantitative real-time RT-PCR (TaqMan) and at the protein level using western blot analysis. Five genes showed lower mRNA expression in aggressive compared to more favorable neuroblastomas (PRKCZ, PRKCB1, EIF4EBP1, $P I K 3 R I$ and $P I K 3 C D$ ) while the opposite was seen for PDGFRA. Clustering analysis shows that the expression levels of these six genes can predict aggressive disease. At the protein level, p110 (encoded by $P I K 3 C D$ ) and p $85 \alpha$ isomers (encoded by $P I K 3 R 1$ ) were more highly expressed in favorable compared to aggressive neuroblastoma. Evaluation of the expression of these PI3K genes can predict aggressive disease, and indicates stage-dependent involvement of PI3K-pathway members in neuroblastoma.
\end{abstract}

\section{Introduction}

The phosphoinositide-3 kinase (PI3K)/Akt pathway participates in many biological processes such as proliferation, apoptosis, differentiation, metabolism and migration (1). The PI3K

Correspondence to: Dr Susanne Fransson, University of Gothenburg, Department of Medical and Clinical Genetics, SU/Sahlgrenska, S-413 45 Gothenburg, Sweden

E-mail: susanne.fransson@clingen.gu.se

Abbreviations: PI3K, phosphoinositide-3 kinase; QPCR, quantitative PCR; INRG, International Neuroblastoma Risk Group; INSS, International Neuroblastoma Staging System Criteria

Key words: neuroblastoma, expression, phosphoinositide-3 kinase, signaling signaling cascade is initiated through activation of receptors with intrinsic tyrosine kinase activity, which leads to generation of the second messenger phosphatidylinositol $(3,4,5)$-trisphosphate $\left(\mathrm{PIP}_{3}\right)$, acting on downstream targets such as PI-dependent kinase (PDK1), integrin-linked kinase (ILK-1) or Akt. Type IA $\mathrm{PI} 3 \mathrm{~K}$ is a heterodimer composed of a p85 regulatory subunit encoded by PIK3R1, PIK3R2 or PIK3R3 and a p110 catalytic subunit; $110 \alpha, \mathrm{p} 110 \beta$ or p1108 encoded by $P I K 3 C A, P I K 3 C B$ and $P I K 3 C D$, respectively. Deregulation of the PI3K/Akt pathway is a recurrent feature in numerous human malignancies with a key role in cancer development, progression and also in resistance to chemotherapy. Over-activity is commonly caused by loss of the tumor suppressor gene PTEN $(2,3)$, oncogenic activation of $P I K 3 C A(4,5)$ and/or over-stimulation by various growth factors like IGF-1, EGF or VEGF (6-8).

Neuroblastoma is a pediatric cancer stemming from immature precursors of the sympathetic nervous system with tumors arising in sympathetic ganglia or adrenal gland (9). Neuroblastoma displays high clinical variability, ranging from more favorable stage 1 tumors to highly aggressive stage 4 tumors with many times fatal outcome. The contribution of PI3K/Akt in the carcinogenesis of neuroblastoma is not fully understood. Mutations in the genes PIK3CA and PTEN frequently reported in other malignancies, are rare in neuroblastoma $(10,11)$ although a few mutations have been reported in PIK3CD (12). PIK3CD also show lower expression in aggressive neuroblastomas compared to neuroblastomas with more favorable biology $(13,14)$. Moreover, further connection to the PI3K/ Akt pathway is seen through Akt, which is found to be activated in neuroblastoma (15) in an outcome-correlated manner (16). There are several other markers that correlate to grade of disease and/or outcome, such as expression of the different Trk-receptors $(17)$, degree of neural differentiation $(18,19)$ or genetic aberrations such as $1 \mathrm{p}$ deletion, 11q deletion, gain of $17 \mathrm{q}$ and amplification of the oncogene MYCN (20). PI3K signaling has effect on Mycn protein stability through inactivation of GSK $3 \beta$ and inhibition of PI3K destabilized Mycn and prevented tumor progression in a murine model of neuroblastoma (21).

$\mathrm{PI} 3 \mathrm{~K}$ inhibition is considered to be one of the most promising targeted therapies for cancer, thus the understanding of the molecular pathology of the individual tumors will be essential to match patients with PI3K inhibitors of differing selectivity profiles. In this study we explored the expression of 
Table I. Clinical data.

Methods

\begin{tabular}{|c|c|c|c|c|c|c|c|c|c|}
\hline \multirow[b]{2}{*}{ Patient } & \multirow[b]{2}{*}{ INSS } & \multirow[b]{2}{*}{ INRG } & \multirow[b]{2}{*}{ Outcome } & \multirow[b]{2}{*}{$1 \mathrm{p}$ loss } & \multirow[b]{2}{*}{ MNA } & \multirow[b]{2}{*}{$11 q$ loss } & \\
\hline & & & & & & & QPCR & WB & Array \\
\hline $18 \mathrm{E} 1$ & 1 & $\mathrm{~L}$ & NED & Neg & Neg & $\mathrm{Neg}$ & + & & \\
\hline $18 \mathrm{E} 5$ & 1 & $\mathrm{~L}$ & NED & $\mathrm{Neg}$ & $\mathrm{Neg}$ & $\mathrm{Neg}$ & + & & \\
\hline $18 \mathrm{E} 8$ & 1 & $\mathrm{~L}$ & NED & Neg & $\mathrm{Neg}$ & $\mathrm{Neg}$ & + & & \\
\hline 19R1 & 1 & $\mathrm{~L}$ & NED & $\mathrm{Neg}$ & $\mathrm{Neg}$ & $\mathrm{Neg}$ & + & & \\
\hline 30R9 & 1 & $\mathrm{~L}$ & NED & $\mathrm{Neg}$ & $\mathrm{Neg}$ & Neg & + & & \\
\hline 19R6 & 1 & $\mathrm{~L}$ & DOD & Pos & Pos & $\mathrm{Neg}$ & + & & \\
\hline $17 \mathrm{E} 7$ & 2 & $\mathrm{~L}$ & NED & $\mathrm{Neg}$ & $\mathrm{Neg}$ & Neg & + & & \\
\hline 10R6 & 2 & $\mathrm{~L}$ & NED & $\mathrm{Neg}$ & $\mathrm{Neg}$ & Neg & + & & \\
\hline $14 \mathrm{R} 9$ & 2 & $\mathrm{~L}$ & NED & Pos & $\mathrm{Neg}$ & Neg & + & & \\
\hline $25 \mathrm{R} 8$ & 2 & $\mathrm{~L}$ & NED & $\mathrm{Neg}$ & $\mathrm{Neg}$ & Neg & + & & \\
\hline 27R1 & 2 & $\mathrm{~L}$ & NED & $\mathrm{Neg}$ & $\mathrm{Neg}$ & $\mathrm{Neg}$ & + & & \\
\hline 33R7 & 2 & $\mathrm{~L}$ & NED & $\mathrm{Neg}$ & $\mathrm{Neg}$ & $\mathrm{Neg}$ & + & & \\
\hline $8 \mathrm{E} 5$ & 3 & $\mathrm{~L}$ & NED & $\mathrm{Neg}$ & $\mathrm{Neg}$ & $\mathrm{Neg}$ & + & & \\
\hline $16 \mathrm{R} 4$ & 3 & $\mathrm{~L}$ & NED & $\mathrm{Neg}$ & Pos & Neg & + & & \\
\hline 34R5 & 3 & $\mathrm{~L}$ & NED & $\mathrm{Neg}$ & $\mathrm{Neg}$ & NA & + & & \\
\hline 6E9 & 3 & $\mathrm{~L}$ & DOD & Pos & $\mathrm{Neg}$ & Pos & + & & \\
\hline 13E6 & 3 & $\mathrm{~L}$ & DOD & Pos & Pos & Pos & + & & \\
\hline $15 \mathrm{E} 1$ & 4 & M & NED & Pos & Pos & Neg & + & & \\
\hline $10 \mathrm{E} 6$ & 4 & M & NED & Pos & Pos & Neg & + & & \\
\hline 17R3 & 4 & M & NED & $\mathrm{Neg}$ & $\mathrm{Neg}$ & NA & + & & \\
\hline $25 \mathrm{R} 3$ & 4 & M & NED & $\mathrm{Neg}$ & $\mathrm{Neg}$ & $\mathrm{Neg}$ & + & & \\
\hline $29 \mathrm{R} 2$ & 4 & M & NED & Pos & Pos & $\mathrm{Neg}$ & + & & \\
\hline $32 \mathrm{R} 2$ & 4 & M & NED & Pos & $\mathrm{Neg}$ & Pos & + & & \\
\hline $40 \mathrm{R} 2$ & 4 & M & NED & $\mathrm{Neg}$ & $\mathrm{Neg}$ & $\mathrm{Neg}$ & + & & \\
\hline 4E1 & 4 & M & DOD & $\mathrm{Neg}$ & $\mathrm{Neg}$ & Pos & + & & \\
\hline 3E2 & 4 & $\mathrm{M}$ & DOD & $\mathrm{Neg}$ & $\mathrm{Neg}$ & Pos & + & & \\
\hline $12 \mathrm{E} 3$ & 4 & M & DOD & Pos & Pos & $\mathrm{Neg}$ & + & & \\
\hline $16 \mathrm{E} 3$ & 4 & M & DOD & Pos & Pos & $\mathrm{Neg}$ & + & & \\
\hline $11 \mathrm{E} 4$ & 4 & M & DOD & $\mathrm{Neg}$ & $\mathrm{Neg}$ & Pos & + & & \\
\hline $18 \mathrm{E} 4$ & 4 & M & DOD & Pos & Pos & $\mathrm{Neg}$ & + & & \\
\hline $13 \mathrm{R} 0$ & 4 & M & DOD & Pos & Pos & $\mathrm{Neg}$ & + & & \\
\hline 24R3 & 4 & M & DOD & Pos & Pos & NA & + & & \\
\hline 26R8 & 4 & M & DOD & Pos & Pos & NA & + & & \\
\hline $35 \mathrm{R} 2$ & NA & $\mathrm{L}$ & NED & $\mathrm{Neg}$ & $\mathrm{Neg}$ & $\mathrm{Neg}$ & + & & \\
\hline 14E6 & 1 & $\mathrm{~L}$ & NED & $\mathrm{Neg}$ & $\mathrm{Neg}$ & $\mathrm{Neg}$ & + & & + \\
\hline $10 \mathrm{R} 7$ & 1 & $\mathrm{~L}$ & NED & $\mathrm{Neg}$ & $\mathrm{Neg}$ & $\mathrm{Neg}$ & + & & + \\
\hline $35 \mathrm{R} 5$ & 1 & $\mathrm{~L}$ & NED & NA & NA & NA & + & & + \\
\hline $35 \mathrm{R} 8$ & 1 & $\mathrm{~L}$ & NED & $\mathrm{Neg}$ & $\mathrm{Neg}$ & $\mathrm{Neg}$ & + & & + \\
\hline 37R6 & 1 & $\mathrm{~L}$ & NED & $\mathrm{Neg}$ & $\mathrm{Neg}$ & $\mathrm{Neg}$ & + & & + \\
\hline 26R0 & 4 & $\mathrm{M}$ & NED & Pos & Pos & Pos & + & & + \\
\hline 25R9 & 2 & $\mathrm{~L}$ & NED & $\mathrm{Neg}$ & $\mathrm{Neg}$ & $\mathrm{Neg}$ & + & + & + \\
\hline $10 \mathrm{R} 2$ & 4 & M & DOD & Pos & Pos & $\mathrm{Neg}$ & + & + & + \\
\hline $15 \mathrm{R} 3$ & 4 & M & DOD & Pos & $\mathrm{Neg}$ & Pos & + & + & + \\
\hline 34R0 & 4 & M & DOD & Neg & Neg & $\mathrm{Neg}$ & + & + & + \\
\hline 9R9 & 3 & M & DOD & Pos & $\mathrm{Neg}$ & Pos & + & + & \\
\hline $15 \mathrm{E} 7$ & 3 & $\mathrm{~L}$ & DSC & $\mathrm{Neg}$ & $\mathrm{Neg}$ & $\mathrm{Neg}$ & + & + & \\
\hline $15 \mathrm{E} 3$ & 3 & $\mathrm{~L}$ & NED & Neg & Neg & $\mathrm{Neg}$ & + & + & \\
\hline 20R9 & 2 & $\mathrm{~L}$ & NED & $\mathrm{Neg}$ & $\mathrm{Neg}$ & NA & + & + & \\
\hline 27R7 & 2 & $\mathrm{~L}$ & NED & $\mathrm{Neg}$ & $\mathrm{Neg}$ & $\mathrm{Neg}$ & + & + & \\
\hline $25 \mathrm{R} 0$ & 3 & $\mathrm{~L}$ & NED & Neg & Neg & $\mathrm{Neg}$ & + & + & \\
\hline $17 \mathrm{R} 2$ & 4 & M & DOD & $\mathrm{Neg}$ & $\mathrm{Neg}$ & Pos & + & + & \\
\hline 28R8 & 4 & M & DOD & $\mathrm{Neg}$ & $\mathrm{Neg}$ & Pos & + & + & \\
\hline $33 \mathrm{R} 5$ & 1 & $\mathrm{~L}$ & NED & $\mathrm{Neg}$ & $\mathrm{Neg}$ & Neg & & + & \\
\hline $13 \mathrm{E} 8$ & 2 & $\mathrm{~L}$ & NED & Neg & Neg & $\mathrm{Neg}$ & & + & \\
\hline
\end{tabular}


Table I. Continued.

Methods

\begin{tabular}{|c|c|c|c|c|c|c|c|c|c|}
\hline Patient & INSS & INRG & Outcome & $1 \mathrm{p}$ loss & MNA & $11 q$ loss & QPCR & WB & Array \\
\hline $11 \mathrm{R} 4$ & 3 & $\mathrm{~L}$ & DOD & Pos & Pos & $\mathrm{Neg}$ & & + & \\
\hline $16 \mathrm{E} 9$ & 4 & M & DOD & $\mathrm{Neg}$ & Pos & $\mathrm{Neg}$ & & + & \\
\hline $10 \mathrm{R} 8$ & 3 & $\mathrm{~L}$ & DOD & $\mathrm{Neg}$ & $\mathrm{Neg}$ & Pos & & + & \\
\hline 39R1 & 4 & M & NED & Pos & Pos & $\mathrm{Neg}$ & & + & + \\
\hline $26 \mathrm{R} 9$ & 1 & $\mathrm{~L}$ & NED & $\mathrm{Neg}$ & $\mathrm{Neg}$ & $\mathrm{Neg}$ & & & + \\
\hline $11 \mathrm{E} 1$ & 4 & M & NED & $\mathrm{Neg}$ & Neg & Pos & & & + \\
\hline $16 \mathrm{E} 1$ & 1 & $\mathrm{~L}$ & NED & $\mathrm{Neg}$ & Neg & Neg & & & + \\
\hline $23 \mathrm{R} 4$ & 2 & $\mathrm{~L}$ & NED & Neg & Neg & Neg & & & + \\
\hline 36R3 & MS & MS & DOD & $\mathrm{Neg}$ & $\mathrm{Neg}$ & $\mathrm{Neg}$ & & & + \\
\hline
\end{tabular}

INSS, International Neuroblastoma Staging System; INRG, International Neuroblastoma Risk Group; MNA, MYCN amplification; NA, information not available; UF, unfavorable; F, favorable; L, localized; M, metastasized; MS metastasized stage 4S; NED, no evidence of disease; DOD, dead of disease; DSC, dead by surgical complications; QPCR, quantitative real-time PCR; WB, western blot analysis; Neg, negative; Pos, positive.

PI3K/Akt associated genes and found significant differences at both mRNA and protein levels between aggressive and favorable neuroblastoma tumors.

\section{Materials and methods}

RNA purification and $c D N A$ preparation. Fresh frozen tumor samples from patients diagnosed with neuroblastoma and staged according to the International Neuroblastoma Staging System Criteria (INSS) and International Neuroblastoma Risk Group (INRG) were used (Table I). Total-RNA was prepared using Totally RNA (Ambion, St. Austin, TX) or RNeasy mini kit (Qiagen, Hilden, Germany) while genomic DNA were removed with DNA-free kit (Ambion). Purity and integrity of the RNA were assayed with spectrophotometer and RNA 6000 Nano Bioanalyzer (Agilent, Palo Alto, CA) before cDNA synthesis using SuperScript ${ }^{\mathrm{TM}}$ II Reverse Transcriptase (Invitrogen, Carlsbad, CA).

Expression analysis by microarray and real-time RT-PCR. Four total-RNAs run on Affymetrix HU133A platform as described previously (46), and another twelve total-RNAs were run on the Affymetrix HU133plus2 platform by Aros Applied Biotechnology AS (www.arosab.com/). Bioconducter for R 2.9.2 (library BioC 2.4) was used to perform gcRMA normalisation for each GeneChip platform set separately. For each probe-set, the maximum expression values over all samples was determined, and probe-sets that showed very low or no detectable expression levels were filtered out ( $\max 2 \log$ expression $<6$ ). For those probesets overlapping the two GeneChip platforms, a probe-specific normalization between the two platforms was performed based on two individuals run on both platforms. Next, the mean $\log 2$ expression level for each gene symbol was calculated.

A set of 88 genes with known association to the PI3K/Akt pathway were selected (Table II) and a two-sided t-test was performed to identify genes with significant differential expression when comparing neuroblastoma of low stage (stage 1, 2 and $4 S)(n=10)$ to stage $4(n=6)$. Expression of identified genes were verified by quantitative real-time PCR (QPCR) using
TaqMan Low Density arrays in a larger set of tumors; stage 1-2 $(n=21)$, stage $4(n=22)$ and stage $3(n=9)$. Pooled RNA (40 donors) from normal adrenal gland tissue was used as reference (Ambion). QPCR was performed using triplicates with pre-designed primer and probe sets for target genes (PRKCZ: hs.00177051_ml, EIF4EBP1: hs.00607050_ml, PRKZB1: hs.01030676_ml, PDGFRA: hs.00183486_ml, PIK3CD: hs.00192399_ml, PIK3R1: hs.00933163_ml, AKTl: hs.00920503_ml, BAD: hs.00188930_ml, GUSB: hs.99999908_ml) and ABI PRISM ${ }^{\circledR}$ 7900HT Sequence detection system (Applied Biosystems). Quantification was performed using the standard curve method with GUSB ( $\beta$-glucuronidase) as endogenous control for normalization of gene expression. The logarithms of mean expression levels were used in t-tests of microarray and QPCR data. Expression from microarrays was compared using two-tailed t-test while expression of genes in the validation-set was compared using one-tailed t-test. Statistical calculations and boxplots were made with SPSS ver.18 (SPSS, Chicago, IL) and Excel (Microsoft). Fold change was calculated by dividing the corresponding values for stage 4 with that of stage 1 and 2 neuroblastomas. Unsupervised hierarchal clustering of real-time PCR data from six PI3K pathway genes and 52 primary neuroblastoma samples. The heat map was based on Max linkage.

Protein isolation, western blot analysis and antibodies. Fresh frozen neuroblastoma tumors were homogenized using Tissuelyzer (Qiagen) in RIPA lysis buffer supplemented with HALT $^{\mathrm{TM}}$ Phosphatase and protease inhibitor cocktail (Pierce, Rockford, IL) while a ready-made protein lysate for normal adrenal gland (20 pooled donors) was purchased from Clontech (Mountain View, CA). SDS-PAGE and western blot analysis were carried out according to standard procedures using $30 \mu \mathrm{g}$ of total protein lysate. Immunoblotting was performed with rabbit polyclonal antibodies against p $85 \alpha$ (no. 06-496) (Millipore, Billerica, MA) 4e-bp1 (no. 9452) (Cell Signaling Technology, Danvers, MA) and PKC $\beta$ (sc-209), PKC $\zeta$ (sc-216), Pdgfra (sc-338) GAPDH (sc-825778) and p1108 (sc-7176), from Santa Cruz Biotechnology (Santa Cruz, CA). Quantification of proteins was performed with the ImageJ software (available at 
Table II. Tested PI3K/Akt associated genes.

\begin{tabular}{|c|c|c|c|}
\hline Gene & Description & Gene & Description \\
\hline$A D A R$ & Adenosine deaminase, RNA-specific isoform a & $M A P K 1$ & Mitogen-activated protein kinase 1 \\
\hline$A K T 1$ & V-akt murine thymoma viral oncogene homolog 1 & MAPK14 & Mitogen-activated protein kinase 14 \\
\hline$A K T 3$ & V-akt murine thymoma viral oncogene homolog 3 & $M A P K 3$ & Mitogen-activated protein kinase 3 \\
\hline$A P C$ & Adenomatous polyposis coli & MAPK8 & Mitogen-activated protein kinase 8 \\
\hline$B A D$ & BCL2-antagonist of cell death protein & $M T C P 1$ & Mature T-cell proliferation 1 \\
\hline$B T K$ & Bruton agammaglobulinemia tyrosine kinase & MYD88 & Myeloid differentiation primary response gene \\
\hline CASP9 & Caspase 9 isoform alpha preproprotein & $N F K B 1$ & Nuclear factor kappa-B, subunit 1 \\
\hline$C C N D 1$ & Cyclin D1 & NFKBIA & Nuclear factor of kappa light polypeptide gene \\
\hline$C D 14$ & CD14 antigen precursor & $N R A S$ & Neuroblastoma RAS viral (v-ras) oncogene \\
\hline$C D C 42$ & Small GTP binding protein CDC42 & $P A B P C 1$ & Poly(A) binding protein, cytoplasmic 1 \\
\hline$C D K N 1 B$ & Cyclin-dependent kinase inhibitor 1B & PDGFRA & Platelet-derived growth factor receptor alpha \\
\hline CTMP & Carboxyl-terminal modulator protein & PDK1 & 3-phosphoinositide dependent protein kinase-1 \\
\hline CHUK & Conserved helix-loop-helix ubiquitous kinase & $P D K 2$ & Pyruvate dehydrogenase kinase, isozyme 2 \\
\hline CSNK2Al & Casein kinase II alpha 1 subunit & $P I K 3 C A$ & Phosphoinositide-3-kinase, catalytic, alpha \\
\hline$C T N N B 1$ & Catenin (cadherin-associated protein), beta 1 & $P I K 3 C B$ & Phosphoinositide-3-kinase, catalytic, beta \\
\hline CUTL1 & Cut-like homeobox 1 & $P I K 3 C D$ & Phosphoinositide-3-kinase, catalytic, delta \\
\hline$E I F 2 A K 2$ & Eukaryotic translation initiation factor 2-alpha & $P I K 3 C G$ & Phosphoinositide-3-kinase, catalytic, gamma \\
\hline EIF4Al & Eukaryotic translation initiation factor 4A & PIK3R1 & Phosphoinositide-3-kinase, regulatory subunit 1 \\
\hline$E I F 4 B$ & Eukaryotic translation initiation factor 4B & $P I K 3 R 3$ & Phosphoinositide-3-kinase, regulatory subunit 3 \\
\hline EIF4E2 & Eukaryotic translation initiation factor $4 \mathrm{E}$ & $P P 2 A$ & Protein phosphatase 2 , catalytic subunit, alpha \\
\hline EIF4EBP1 & Eukaryotic translation initiation factor $4 \mathrm{E}$ & $P R K C A$ & Protein kinase $\mathrm{C}$, alpha \\
\hline EIF4G1 & Eukaryotic translation initiation factor 4 & PRKCB1 & Protein kinase $\mathrm{C}$, beta isoform 1 \\
\hline ELK1 & ELK1 protein & $P R K C Z$ & Protein kinase $\mathrm{C}$, zeta \\
\hline FASLG & Tumor necrosis factor ligand superfamily member 6 & PTEN & Phosphatase and tensin homolog \\
\hline$F K B P 1 A$ & FK506-binding protein 1A & $P T K 2$ & PTK2 protein tyrosine kinase 2 \\
\hline FOS & C-fos FBJ murine osteosarcoma viral oncogene & PTPN11 & Protein tyrosine phosphatase, non-receptor type \\
\hline FOXO1 & Forkhead box $\mathrm{O} 1$ & $R A C 1$ & Ras-related C 3 botulinum toxin substrate 1 \\
\hline FOXO3 & Forkhead box O3A & $R A F 1$ & V-raf-1 murine leukemia viral oncogene homolog \\
\hline FRAP1 (MTOR) & FK506 binding protein 12-rapamycin associated & RASAl & RAS p21 protein activator 1 \\
\hline GJAl & Connexin 43 & $R B L 2$ & Retinoblastoma-like 2 (p130) \\
\hline GRB10 & Growth factor receptor-bound protein 10 & RHEB & Ras homolog enriched in brain \\
\hline GRB2 & Growth factor receptor-bound protein 2 & RHOA & Ras homolog gene family, member A \\
\hline GSK3B & Glycogen synthase kinase 3 beta & RPS6KA1 & Ribosomal protein S6 kinase, $90 \mathrm{kDa}$, polypeptide \\
\hline$H R A S$ & V-Ha-ras Harvey rat sarcoma viral oncogene & RPS6KB1 & Ribosomal protein S6 kinase, $70 \mathrm{kDa}$, polypeptide \\
\hline HSPB 1 & Heat shock $27 \mathrm{kDa}$ protein 1 & SHCl & SHC (Src homology 2 domain containing) \\
\hline IGF1 & Insulin-like growth factor $1 \mathrm{i}$ & SOS1 & Son of sevenless homolog 1 \\
\hline$I G F 1 R$ & Insulin-like growth factor 1 receptor & $S R F$ & Serum response factor \\
\hline$I L K$ & Integrin-linked kinase & TIRAP & Toll-interleukin 1 receptor domain-containing \\
\hline IRAK1 & Interleukin-1 receptor-associated kinase 1 & $T L R 4$ & Toll-like receptor 4 \\
\hline IRS1 & Insulin receptor substrate 1 & TOLLIP & Toll interacting protein \\
\hline ITGBI & Integrin beta 1 isoform 1B precursor & TSC1 & Tuberous sclerosis 1 protein \\
\hline$J U N$ & Jun oncogene & TSC2 & Tuberous sclerosis 2 \\
\hline KRAS & Ras family small GTP binding protein K-Ras & WASL & Wiskott-Aldrich syndrome gene-like protein \\
\hline$M A P 2 K 1$ & Mitogen-activated protein kinase kinase 1 & YWHAH & Tyrosine 3-monooxygenase/tryptophan \\
\hline
\end{tabular}

http://rsb.info.nih.gov/ij). GAPDH was used for normalization in calculation of relative expression. The logarithms of expression levels were calculated and the difference between groups was assessed by a two-tailed independent-samples t-test.

\section{Results}

mRNA levels of six PI3K-pathway genes differs between neuroblastoma stages. Analysis of Affymetrix oligo micro- array data on a panel of neuroblastoma tumors revealed differential expression between low stage (1,2 and 4S) and stage 4 patients with statistical significance $(\mathrm{p}<0.05)$ for 8 out of 88 genes associated with PI3K/Akt signaling (Table III). Expression of these genes were validated in a larger set of primary neuroblastoma samples using QPCR and the pattern of expression was confirmed for PRKCZ, EIF4EBPI, PRKCB1, $P I K 3 C D, P I K 3 R 1$, which showed lower expression in stage 4 compared to stage 1-2 tumors, and PDGFRA, which showed 
Table III. Results from microarray and QPCR.

\begin{tabular}{|c|c|c|c|c|c|}
\hline \multirow[b]{2}{*}{ Gene } & \multirow{2}{*}{$\begin{array}{c}\text { Chromosomal } \\
\text { localization }\end{array}$} & \multicolumn{2}{|c|}{ Microarray } & \multicolumn{2}{|c|}{ QPCR } \\
\hline & & Fold change & P-value* & Fold change & P-value \\
\hline$P R K C Z$ & $1 \mathrm{p} 36$ & 0.46 & 0.02 & 0.52 & 0.0003 \\
\hline EIF4EBPI & $8 \mathrm{p} 12$ & 0.60 & 0.02 & 0.64 & 0.006 \\
\hline PRKCB1 & $16 \mathrm{p} 11$ & 0.19 & 0.02 & 0.28 & 0.005 \\
\hline PDGFRA & $4 q 12$ & 10.40 & 0.02 & 2.46 & 0.01 \\
\hline$P I K 3 C D$ & $1 \mathrm{p} 36$ & 0.31 & 0.001 & 0.61 & 0.03 \\
\hline PIK3RI & $5 q 13$ & 0.44 & 0.03 & 0.36 & 0.03 \\
\hline$A K T 1$ & $14 q 32$ & 0.77 & 0.03 & 1.05 & 0.43 \\
\hline$B A D$ & $11 \mathrm{q} 13$ & 0.46 & 0.004 & 0.98 & 0.40 \\
\hline$G U S B$ & $7 q 11$ & - & - & - & - \\
\hline
\end{tabular}

"Two-tailed t-test; ${ }^{* *}$ one-tailed t-test.
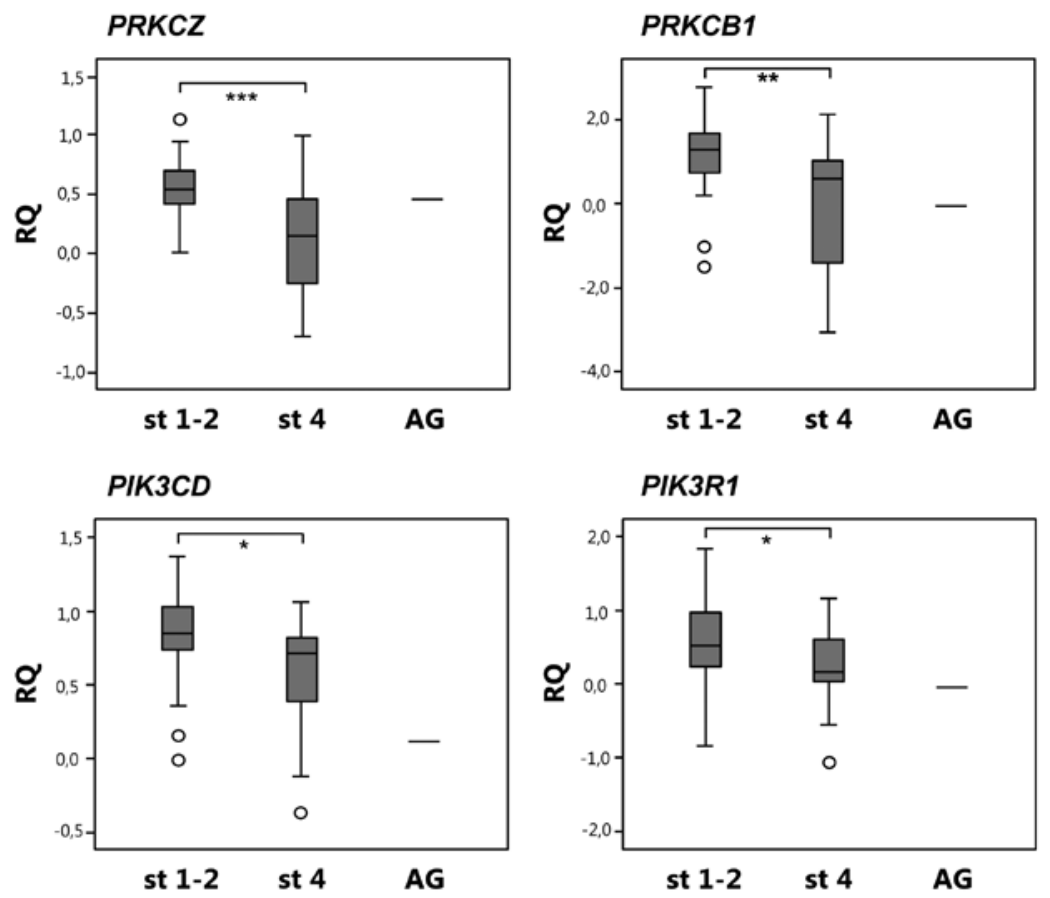

EIF4EBP1
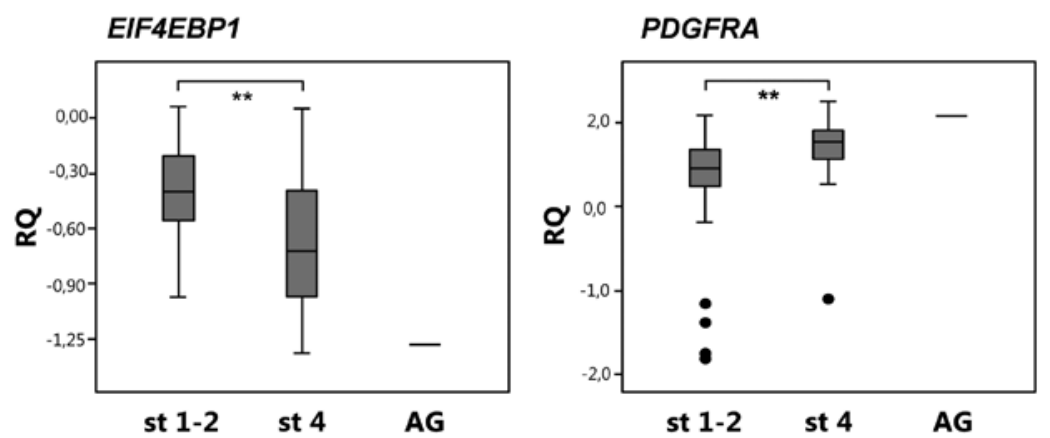

Figure 1. Relative mRNA expression of PI3K/Akt genes according to QPCR. Boxplots showing logarithmic values after normalization with GUSB. Boxplot explanation; upper hinge of the box, 75th percentile; lower hinge of the box, 25th percentile; thick horizontal line within box, median. The whiskers are indicating range, open circles represent outliers while filled circles represent extremes. ${ }^{*} \mathrm{p} \leq 0.05 ;{ }^{* *} \mathrm{p} \leq 0.01 ;{ }^{* * *} \mathrm{p} \leq 0.001$. AG, adrenal gland; RQ, relative quantitation.

higher expression in stage 4 compared to stage 1-2 tumors (Fig. 1, Table III).
Clustering of six PI3K-pathway genes. Unsupervised hierarchal clustering using Max linkage of real-time PCR data from 


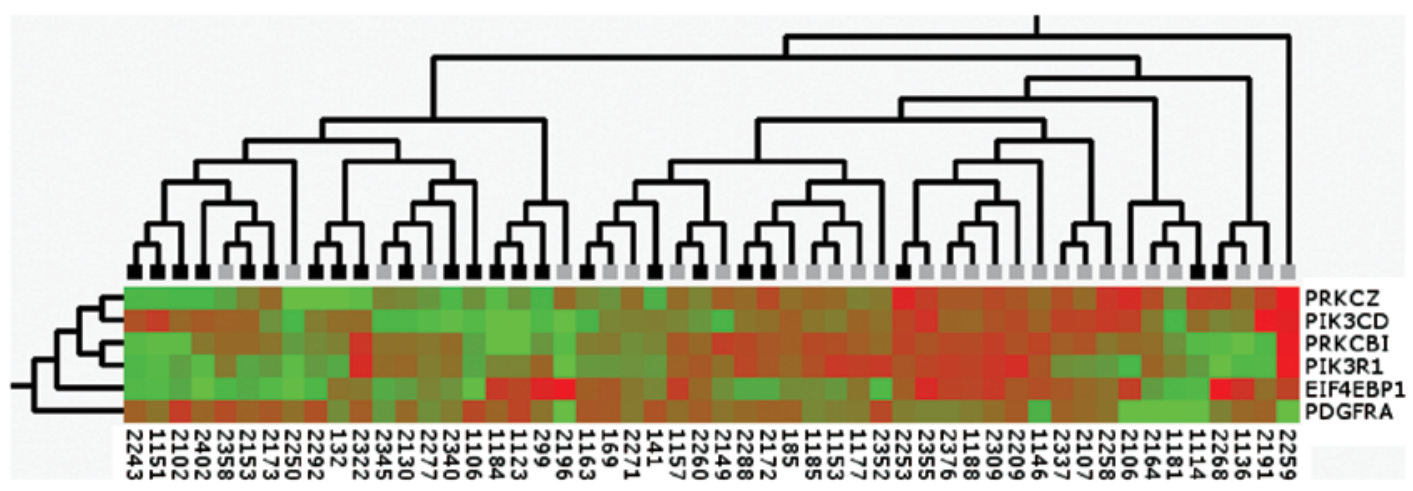

Figure 2. Unsupervised hierarchal clustering of real-time PCR data from six PI3K pathway genes and 52 primary neuroblastoma samples. The heat map was based on Max linkage, and colour scale is based on standard deviations (sd) and ranges from $+2 \mathrm{sd}$ (red) to $-2 \mathrm{sd}$ (green). Cases are divided into two INRG subgroups, marked by top squares: grey, L, localized; black, M, metastasized.
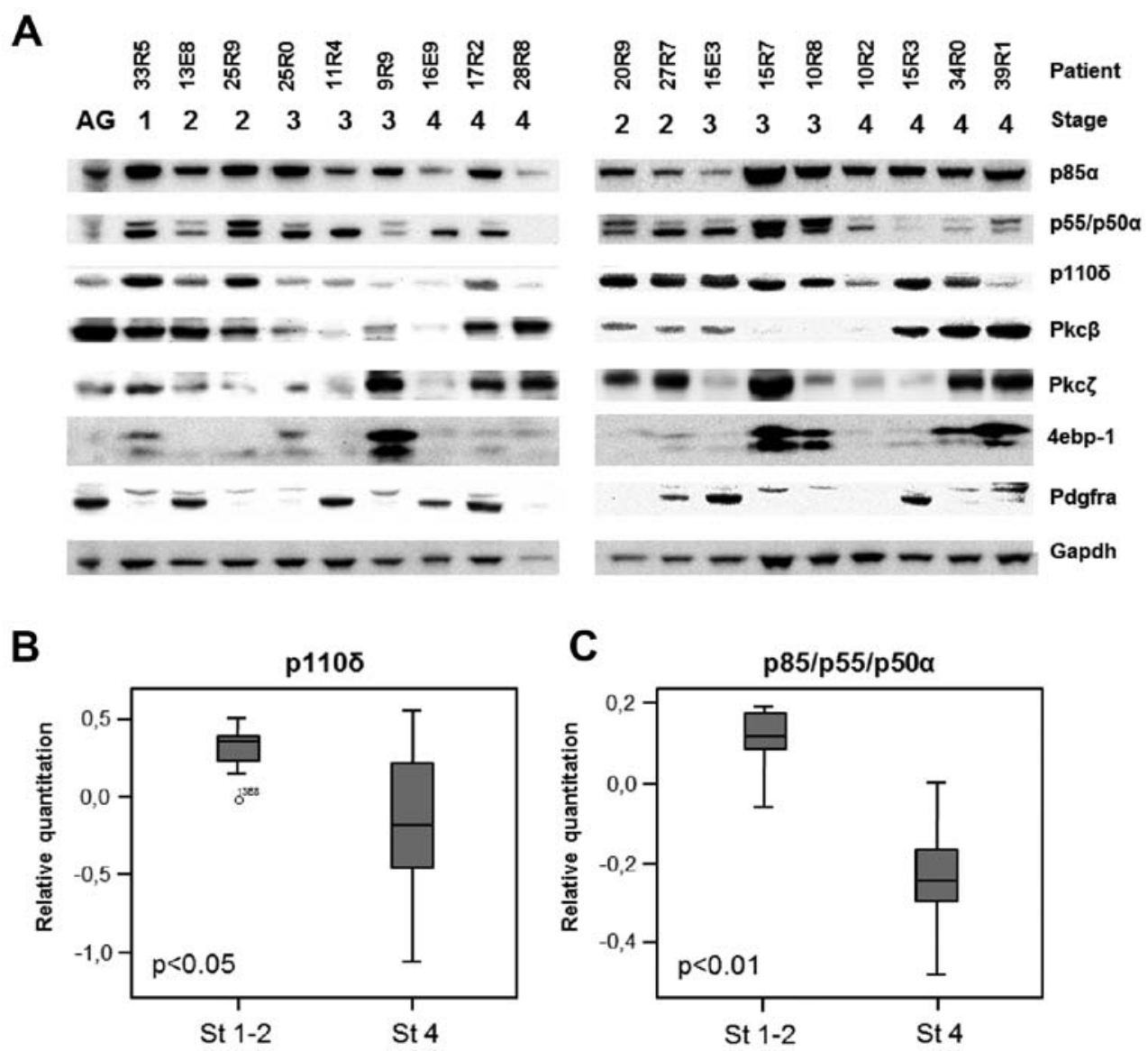

Figure 3. Western blot analysis showing proteins encoded by differentially expressed genes. (A) Western blot analysis showing the protein levels encoded by the genes PIK3R1, PIK3CD, PRKCB1, PRKCZ, EIF4EBP1 and PDGFRA in neuroblastomas of different stages. (B and C) p1108 (PIK3CD) and p85a (PIK3R1) show significant difference between aggressive and favorable neuroblastomas. AG, adrenal gland.

PRKCZ, EIF4EBPI,PRKCBI,PIK3CD, PIK3RI and PDGFRA in 52 primary tumor samples showed that the expression levels of these genes cluster neuroblastomas into metastasizing and localized tumors (Fig. 2).

Low p110ठ and p85a protein levels in aggressive neuroblastoma. To further explore the proteins encoded by the differential expressed genes we performed western blot analysis on lysates from 18 primary neuroblastoma tumors and normal adrenal gland. All proteins except 4e-bp1 were detectable in adrenal gland and to various extents in neuroblastoma tumors (Fig. 3A). p1108 (encoded by PIK3CD) was detected in all stages, however overall protein levels of p110 $\mathrm{d}$ was significantly lower in stage 4 compared to stage 1-2 neuroblastomas ( $\mathrm{p}=0.04)$ (Fig. 3B). The overall protein levels of $\mathrm{p} 85 \alpha$ isomers were significantly lower in stage 4 compared to stage 1-2 neuroblastoma $(\mathrm{p}=0.0015)$ 
(Fig. 3C). No other proteins encoded by the genes differently expressed on mRNA-level showed significant differences in protein levels in these 18 tested neuroblastoma protein samples.

\section{Discussion}

The PI3K/Akt pathway is central for numerous cellular functions and it is frequently deregulated in human cancers. This pathway is also suggested to be an important player in neuroblastoma development and/or progression and we therefore investigated different actors in PI3K/Akt signaling in primary tumors through analysis at the mRNA and protein level. Five of 88 investigated genes associated to PI3K/Akt signaling pathway showed higher levels of mRNA expression in stage 1-2 neuroblastomas compared to stage 4; EIF4EBPI, PRKCZ, PRKCB1, $P I K 3 R I$ and $P I K 3 C D$. It is notable that the decreased expression of PIK3CD and $P R K C Z$ in stage 4 neuroblastoma may be due to their chromosomal localization at $1 \mathrm{p} 36$, a region frequently deleted in stage 4 neuroblastoma.

EIF4EBPI encodes 4e-bp1, a repressor protein that inhibits the eukaryotic translation initiation factor 4E (eIF4E). High expression of EIF4EBP1 in both favorable and unfavorable neuroblastomas compared to adrenal gland indicates a general upregulation with higher mRNA levels in stage 1-2 compared to stage 4 neuroblastoma (Fig. 1). It is possible that lower expression of EIF4EBPI mimics the physiological relevance of phosphorylation of 4e-bp1 since both is expected to reduce translational inhibition.

The mRNA expression of $P R K C B 1$ and $P R K C Z$, encoding $\mathrm{PKC} \beta$ and $\mathrm{PKC} \zeta$, respectively, were lower in stage 4 compared to stage 1-2 (Fig. 1). Members of the PKC family have unique and even opposite effects on cell growth, survival and differentiation (22-24). PKC $\beta$ stimulates growth and proliferation in neuroblastoma (25) although upregulation of both $\mathrm{PKC} \beta$ and PKC $\zeta$ was noticed under euxanthone-induced differentiation of a neuroblastoma cell line (26) and PKC $\beta$ activation induced apoptosis in HL60-cells (27). $\mathrm{PKC} \zeta$ participate in negative regulation of IRS-1 (28) and have shown proapoptotic functions in ovarian cancer (29). On the other hand, siRNA silencing of $P R K C Z$ impairs migration and invasion in glioblastoma, indicating a role in metastasis (30). This suggests different roles of the PKC isoforms depending on stimuli, and that further effort is needed to elucidate the functions of $P R K C Z$ and $P R K C B 1$ in neuroblastoma.

PDGFRA encodes a cell surface tyrosine kinase receptor important in development of the neural crest and has also been shown to be important in neuroblastoma differentiation $(31,32)$. Moreover, it has also been found to be downregulated during neural differentiation (32). We found PDGFRA to be expressed in all stages even though significantly higher in stage 4 compared to stage 1-2 neuroblastoma, probably explained by the undifferentiated character of all neuroblastomas, especially stage 4. Since PDGFRA also has been found to be mutated or overexpressed in cancer and contribute to cancer development by autocrine or paracrine signaling mechanisms, this could also contribute to the pathogenesis of neuroblastoma (33).

Pten activity can be modulated by the p 85 subunit of the PI3K $(34,35)$, which also enhances the phosphatase activity of Pten (36). Consequently, decreased levels of p85 leads to dimin- ished Pten activity and hence increased phosphorylation of Akt. In our material, expression of PIK3RI, encoding three different p85 $\alpha$ isomers, was indeed decreased in stage 4 tumors compared to stage 1-2 both on mRNA and on protein level (Figs. 1 and 3). In hepatocellular carcinoma PIK3RI levels were inversely correlated with grade of malignancy, consistent with reports of tumor suppressing functions of p85 (37,38). Besides modulation of Pten, p85 stabilizes and inhibits the p110 $\alpha$ isoform (39) and mutations in the $\mathrm{SH} 2$-domain of $\mathrm{p} 85$ has been shown to release the inhibitory effect of p110 $\alpha$ and leads to constitutive activation of Akt (40-42).

Both mRNA and protein levels from PIK3CD/p1108 are decreased in stage 4 neuroblastomas compared to stage 1-2 as described by us and others previously $(13,14)$. Signaling through $\mathrm{PI} 3 \mathrm{~K}$ is required in neural development (43-46) and possibly the $\delta$-isoform could be important in neuroblast differentiation since higher levels of p1108 was detected in stage 1-2 neuroblastoma, commonly expressing more markers of neural differentiation. However, the contribution of the different p110 isoforms in neural differentiation is not fully understood and requires further attention.

Although the molecular mechanisms underlying neuroblastoma are slowly being uncovered, neuroblastoma is still fatal in many cases. In this study we have detected differential expression of several members of the PI3K/Akt pathway on mRNA and/or protein level. Since neuroblastoma is a heterogeneous disease, tumor initiation and progression could occur through activation of different signaling pathways. From the present study we conclude that expression evaluation of a few genes involved in the PI3K-pathway can predict aggressive disease, and our findings indicate a stage-dependent involvement of the PI3K-pathway in neuroblastoma.

\section{Acknowledgements}

We thank the Sahlgenska Gothenburg Genomics Core Facility for access to the ABI PRISM ${ }^{\circledR} 7900 \mathrm{HT}$ System and Grissel Faura for technical assistance. This study was supported by grants from the Swedish Cancer Society, the Swedish Children's Cancer Fund, the Sahlgrenska University Hospital Foundation, the Assar Gabrielsson Foundation, Gunvor and Ivan Svensson's Foundation, Åke Wiberg's Foundation, Mary Beves Foundation for research in childhood cancer and Frimurare Barnhusdirektionen.

\section{References}

1. Engelman JA, Luo J and Cantley LC: The evolution of phosphatidylinositol 3-kinases as regulators of growth and metabolism. Nat Rev Genet 7: 606-619, 2006.

2. Saal LH, Johansson P, Holm K, et al: Poor prognosis in carcinoma is associated with a gene expression signature of aberrant PTEN tumor suppressor pathway activity. Proc Natl Acad Sci USA 104: 7564-7569, 2007.

3. Tang JM, He QY, Guo RX and Chang XJ: Phosphorylated Akt overexpression and loss of PTEN expression in non-small cell lung cancer confers poor prognosis. Lung Cancer 51: 181-191, 2006.

4. Aleskandarany MA, Rakha EA, Ahmed MA, et al: PIK3CA expression in invasive breast cancer: a biomarker of poor prognosis. Breast Cancer Res Treat 122: 45-53, 2010.

5. Kato S, Iida S, Higuchi T, et al: PIK3CA mutation is predictive of poor survival in patients with colorectal cancer. Int J Cancer 121: 1771-1778, 2007. 
6. Chapuis N, Tamburini J, Cornillet-Lefebvre P, et al: Autocrine IGF-1/IGF-1R signaling is responsible for constitutive PI3K/Akt activation in acute myeloid leukemia: therapeutic value of neutralizing anti-IGF-1R antibody. Haematologica 95: 415-423, 2010.

7. Muders MH, Zhang H, Wang E, Tindall DJ and Datta K: Vascular endothelial growth factor-C protects prostate cancer cells from oxidative stress by the activation of mammalian target of rapamycin complex-2 and AKT-1. Cancer Res 69 : 6042-6048, 2009

8. Puri N and Salgia R: Synergism of EGFR and c-Met pathways, cross-talk and inhibition, in non-small cell lung cancer. J Carcinog 7: 9, 2008.

9. De Preter K, Vandesompele J, Heimann P, et al: Human fetal neuroblast and neuroblastoma transcriptome analysis confirms neuroblast origin and highlights neuroblastoma candidate genes. Genome Biol 7: R84, 2006.

10. Dam V, Morgan BT, Mazanek P and Hogarty MD: Mutations in PIK3CA are infrequent in neuroblastoma. BMC Cancer 6: 177, 2006.

11. Moritake H, Horii Y, Kuroda H and Sugimoto T: Analysis of PTEN/MMAC1 alteration in neuroblastoma. Cancer Genet Cytogenet 125: 151-155, 2001.

12. Caren H, Fransson S, Ejeskar K, Kogner P and Martinsson T: Genetic and epigenetic changes in the common 1p36 deletion in neuroblastoma tumours. Br J Cancer 97: 1416-1424, 2007.

13. Boller D, Schramm A, Doepfner KT, et al: Targeting the phosphoinositide 3-kinase isoform p110delta impairs growth and survival in neuroblastoma cells. Clin Cancer Res 14: 1172-1181, 2008.

14. Fransson S, Martinsson $\mathrm{T}$ and Ejeskar K: Neuroblastoma tumors with favorable and unfavorable outcomes: significant differences in mRNA expression of genes mapped at $1 \mathrm{p} 36.2$. Genes Chromosomes Cancer 46: 45-52, 2007.

15. Johnsen JI, Segerstrom L, Orrego A, et al: Inhibitors of mammalian target of rapamycin downregulate $\mathrm{MYCN}$ protein expression and inhibit neuroblastoma growth in vitro and in vivo. Oncogene 27: 2910-2922, 2008.

16. Opel D, Poremba C, Simon T, Debatin KM and Fulda S: Activation of Akt predicts poor outcome in neuroblastoma Cancer Res 67: 735-745, 2007.

17. Brodeur GM, Minturn JE, Ho R, et al: Trk receptor expression and inhibition in neuroblastomas. Clin Cancer Res 15: 3244-3250, 2009.

18. Fredlund E, Ringner M, Maris JM and Pahlman S: High Myc pathway activity and low stage of neuronal differentiation associate with poor outcome in neuroblastoma. Proc Natl Acad Sci USA 105: 14094-14099, 2008.

19. Hedborg F, Bjelfman C, Sparen P, Sandstedt B and Pahlman S: Biochemical evidence for a mature phenotype in morphologically poorly differentiated neuroblastomas with a favourable outcome. Eur J Cancer 31A: 435-443, 1995.

20. Brodeur GM: Neuroblastoma: biological insights into a clinical enigma. Nat Rev Cancer 3: 203-216, 2003.

21. Chesler L, Schlieve C, Goldenberg DD, et al: Inhibition of phosphatidylinositol 3-kinase destabilizes Mycn protein and blocks malignant progression in neuroblastoma. Cancer Res 66: 8139-8146, 2006.

22. Yamamoto M, Acevedo-Duncan M, Chalfant CE, Patel NA, Watson JE and Cooper DR: The roles of protein kinase $\mathrm{C}$ beta I and beta II in vascular smooth muscle cell proliferation. Exp Cell Res 240: 349-358, 1998.

23. Borner C, Ueffing M, Jaken S, Parker PJ and Weinstein IB: Two closely related isoforms of protein kinase $\mathrm{C}$ produce reciprocal effects on the growth of rat fibroblasts. Possible molecular mechanisms. J Biol Chem 270: 78-86, 1995.

24. Zeidman R, Pettersson L, Sailaja PR, et al: Novel and classical protein kinase $\mathrm{C}$ isoforms have different functions in proliferation, survival and differentiation of neuroblastoma cells. Int J Cancer 81: 494-501, 1999

25. Svensson K, Zeidman R, Troller U, Schultz A and Larsson C: Protein kinase $\mathrm{C}$ betal is implicated in the regulation of neuroblastoma cell growth and proliferation. Cell Growth Differ 11: 641-648, 2000

26. Mak NK, Lung HL, Wong RN, Leung HW, Tsang HY and Leung KN: Expression of protein kinase $\mathrm{C}$ isoforms in euxanthone-induced differentiation of neuroblastoma cells. Planta Med 67: 400-405, 2001.
27. Macfarlane DE and Manzel L: Activation of beta-isozyme of protein kinase $\mathrm{C}$ (PKC beta) is necessary and sufficient for phorbol ester-induced differentiation of HL-60 promyelocytes. Studies with PKC beta-defective PET mutant. J Biol Chem 269: 4327-4331, 1994.

28. Liu YF, Paz K, Herschkovitz A, et al: Insulin stimulates PKCzeta-mediated phosphorylation of insulin receptor substrate-1 (IRS-1). A self-attenuated mechanism to negatively regulate the function of IRS proteins. J Biol Chem 276 14459-14465, 2001.

29. Nazarenko I, Jenny M, Keil J, et al: Atypical protein kinase C zeta exhibits a proapoptotic function in ovarian cancer. Mol Cancer Res 8: 919-934, 2010.

30. Guo H, Gu F, Li W, et al: Reduction of protein kinase C zeta inhibits migration and invasion of human glioblastoma cells. J Neurochem 109: 203-213, 2009.

31. Mei Y, Wang Z, Zhang L, et al: Regulation of neuroblastoma differentiation by forkhead transcription factors FOXO1/3/4 through the receptor tyrosine kinase PDGFRA. Proc Natl Acad Sci USA 109: 4898-4903, 2012.

32. Pahlman S, Johansson I, Westermark B and Nister $M$ : Platelet-derived growth factor potentiates phorbol ester-induced neuronal differentiation of human neuroblastoma cells. Cell Growth Differ 3: 783-790, 1992.

33. Yu J, Ustach C and Kim HR: Platelet-derived growth factor signaling and human cancer. J Biochem Mol Biol 36: 49-59, 2003.

34. Barber DF, Alvarado-Kristensson M, Gonzalez-GarciaA, Pulido R and Carrera AC: PTEN regulation, a novel function for the p85 subunit of phosphoinositide 3-kinase. Sci STKE 2006: pe 49, 2006.

35. Rabinovsky R, Pochanard P, McNear C, et al: p85 associates with unphosphorylated PTEN and the PTEN-associated complex. Mol Cell Biol 29: 5377-5388, 2009.

36. Chagpar RB, Links PH, Pastor MC, et al: Direct positive regulation of PTEN by the $\mathrm{p} 85$ subunit of phosphatidylinositol 3-kinase. Proc Natl Acad Sci USA 107: 5471-5476, 2010.

37. Taniguchi CM, Winnay J, Kondo T, et al: The phosphoinositide 3-kinase regulatory subunit p85alpha can exert tumor suppressor properties through negative regulation of growth factor signaling. Cancer Res 70: 5305-5315, 2010.

38. Luo $\mathrm{J}$ and Cantley LC: The negative regulation of phosphoinositide 3-kinase signaling by $\mathrm{p} 85$ and it's implication in cancer. Cell Cycle 4: 1309-1312, 2005.

39. Yu J, Zhang Y, McIlroy J, Rordorf-Nikolic T, Orr GA and Backer JM: Regulation of the p85/p110 phosphatidylinositol 3'-kinase: stabilization and inhibition of the p110alpha catalytic subunit by the p85 regulatory subunit. Mol Cell Biol 18: 1379-1387, 1998

40. Shekar SC, Wu H, Fu Z, et al: Mechanism of constitutive phosphoinositide 3-kinase activation by oncogenic mutants of the p85 regulatory subunit. J Biol Chem 280: 27850-27855, 2005.

41. Jimenez C, Jones DR, Rodriguez-Viciana P, et al: Identification and characterization of a new oncogene derived from the regulatory subunit of phosphoinositide 3-kinase. EMBO J 17: 743-753, 1998.

42. Philp AJ, Campbell IG, Leet C, et al: The phosphatidylinositol 3'-kinase p85alpha gene is an oncogene in human ovarian and colon tumors. Cancer Res 61: 7426-7429, 2001.

43. Lopez-Carballo G, Moreno L, Masia S, Perez P and Barettino D: Activation of the phosphatidylinositol 3-kinase/Akt signaling pathway by retinoic acid is required for neural differentiation of SH-SY5Y human neuroblastoma cells. J Biol Chem 277: 25297-25304, 2002.

44. Evangelopoulos ME, Weis J and Kruttgen A: Signalling pathways leading to neuroblastoma differentiation after serum withdrawal: HDL blocks neuroblastoma differentiation by inhibition of EGFR. Oncogene 24: 3309-3318, 2005.

45. Evangelopoulos ME, Weis J and Kruttgen A: Mevastatininduced neurite outgrowth of neuroblastoma cells via activation of EGFR. J Neurosci Res 87: 2138-2144, 2009.

46. Wilzen A, Nilsson S, Sjoberg RM, Kogner P, Martinsson T and Abel F: The Phox 2 pathway is differentially expressed in neuroblastoma tumors, but no mutations were found in the candidate tumor suppressor gene PHOX2A. Int J Oncol 34: 697-705, 2009. 